\title{
Is it a New Late Complication of Transcatheter Aortic Valve Implantation?
}

\author{
Özgen Şafak, Ilgın Karaca'1, Murat Özgüler² \\ Department of Cardiology, Burdur State Hospital, Burdur, Departments of ${ }^{1}$ Cardiology and ${ }^{2}$ Cardiovascular Surgery, Firat University, Elazığ, Turkey
}

\section{Abstract}

Transcatheter aortic valve implantation (TAVI) is a novel method for patients with severe aortic stenosis at high surgical risk. Although short- and medium-term outcomes after TAVI are encouraging, long-term data on valve function and clinical outcomes are limited. Hence, our case can make a contribution to literature. An 80-year-old patient with severe aortic stenosis underwent TAVI in our clinic in October 2015. After 5 months, she admitted to our emergency department with severe dyspnea. Her symptoms were started within 2 days and getting worse day by day. Echocardiography revealed us a severe aortic regurgitation due to dislocation of the valve to the left ventricular outflow tract side. After diagnosis, aortic regurgitation was treated by valve-in-valve technique. TAVI may provide an alternative therapeutic approach to ineligible or poor surgical candidates of degenerative aortic stenosis. However, this technique also has some complications such as mortality, atrioventricular (AV) block, stroke, and coronary obstruction. Valve embolization is an another rare complication of this procedure and usually can be prevented by careful preprocedure annulus measurements, stable lead positioning for rapid pacing, optimal valve positioning, full balloon inflation at the time of valve deployment, and complete balloon deflation before stopping rapid pacing. At this point, our case became important for the complication literature with its time, about 5 months. Because it is the more recently used technique, we need much more time to detect the usefulness and complications of TAVI and learn how to avoid these complications.

Keywords: Aortic stenosis, transcatheter aortic valve implantation, valve migration

\section{INTRODUCTION}

Degenerative aortic stenosis is the most commonly acquired valvular heart disease in adults, with a prevalence of $4 \%$ in patients over 80 years of age. In symptomatic patients, surgical aortic valve replacement has been the treatment of choice for 40 years. ${ }^{[1]}$ However, especially for the older ages, up to $30 \%-60 \%$ of cases are considered too high risk for open-heart surgery. ${ }^{[2-4]}$ Transcatheter aortic valve implantation (TAVI) has been introduced in 2002 by Cribier et al. to treat older surgical high-risk patients with severe symptomatic aortic stenosis. ${ }^{[5]}$

The EuroSCORE and Society of Thoracic Surgeons (STS) score are the most widely used risk scores to predict operative mortality in cardiac surgery. ${ }^{[6]}$

\section{Case Report}

The patient with severe aortic stenosis was hospitalized; after a multidisciplinary discussion by the heart team, the patient was planned for TAVI using the Edwards SAPIEN valve through a transfemoral approach [Figure 1]. When

\begin{tabular}{|l|l|}
\hline \multicolumn{3}{c|}{ Access this article online } \\
\hline Quick Response Code: & Website: \\
& \\
http://www.ijcva.com
\end{tabular}

this procedure was administered, the patient was morbidly obese with 40.8 body mass index (BMI). After 5 months, she was admitted to our hospital with severe dyspnea and decreased effort capacity that worsened day by day. Her medical therapy was started immediately and evaluated for the reason. During her examination, echocardiography revealed us a severe aortic regurgitation due to dislocation of the vale to the left ventricular outflow tract. After hemodynamic stability facilitated, she was taken to laboratory and $26 \mathrm{~mm}$ CoreValve Evolut R was implanted as valve-in-valve technique [Figures 2 and 3]. No acute complication occurred; after 5-day hospitalization, she was discharged. At the second administration, her BMI was 29.2; she lost $29 \mathrm{~kg}$ in 7 weeks, which can be the cause of valve migration.

Address for correspondence: Dr. Özgen Şafak, Department of Cardiology, Burdur State Hospital, Burdur, Turkey. E-mail: ozgen_safak@yahoo.com

This is an open access journal, and articles are distributed under the terms of the Creative Commons Attribution-NonCommercial-ShareAlike 4.0 License, which allows others to remix, tweak, and build upon the work non-commercially, as long as appropriate credit is given and the new creations are licensed under the identical terms.

For reprints contact: reprints@medknow.com

How to cite this article: Şafak Ö, Karaca I, Özgüler M. Is it a new late complication of transcatheter aortic valve implantation?. Int J Cardiovasc Acad 2018;4:32-4. 


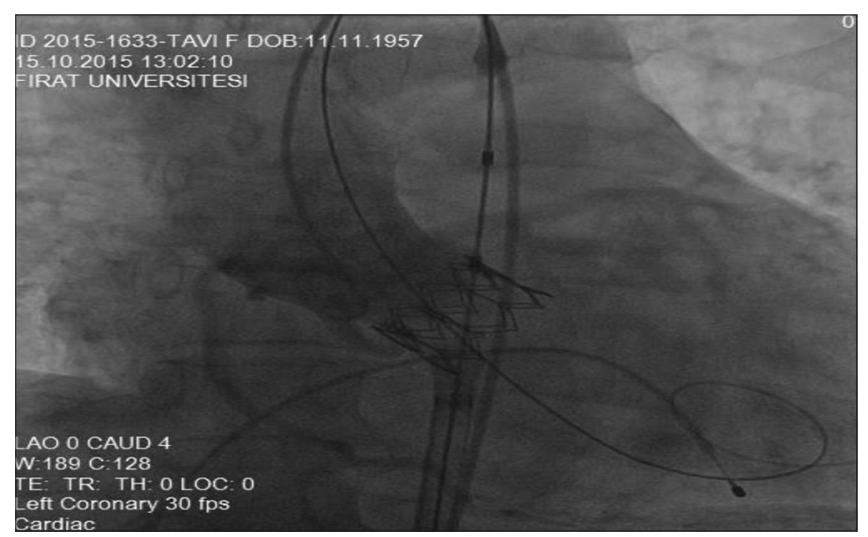

Figure 1: First transcatheter aortic valve implantation administration

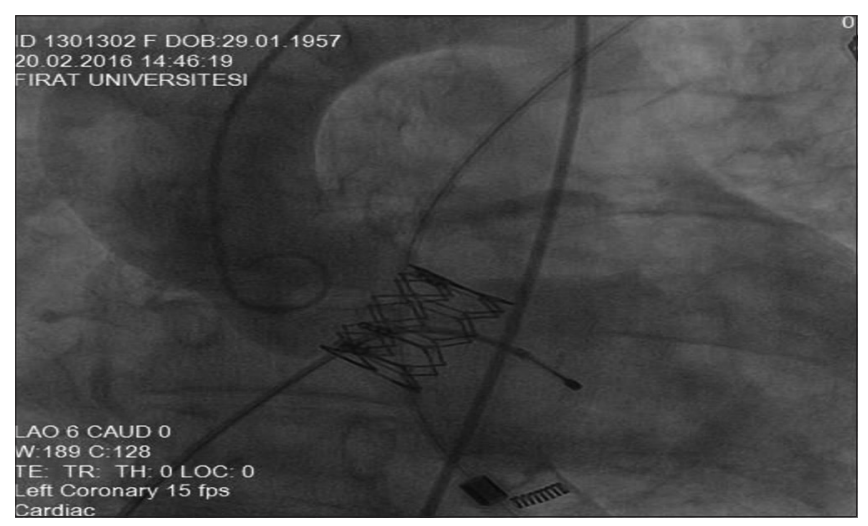

Figure 2: Migration of valve

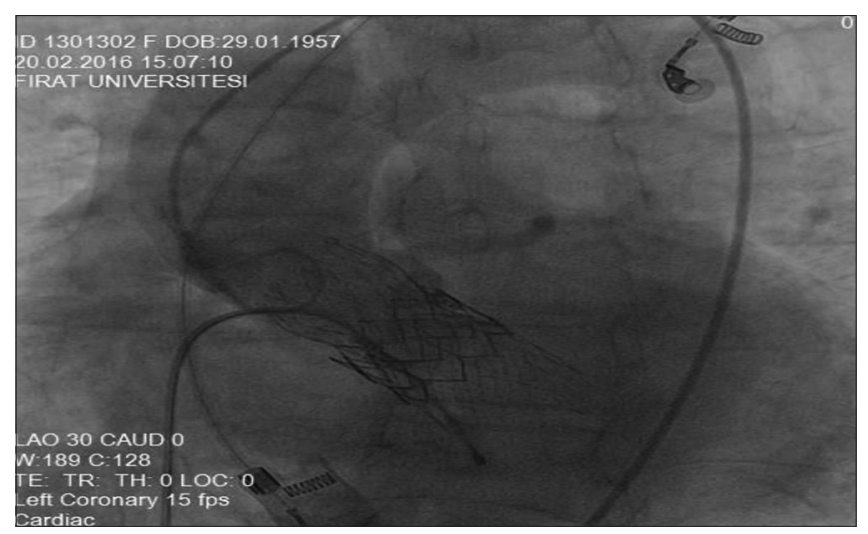

Figure 3: Valve in valve

\section{DISCUSSION}

The recently introduced Valve Academic Research Consortium $1^{[7]}$ and $2^{[8]}$ criteria may help to standardize the documentation of postoperative complications such as myocardial infarction, stroke, bleeding, acute kidney injury, vascular complications, and valve performance, as well as the risk of mortality. Malpositioning, valve migration/embolization, conversion to open surgery, renal failure, need for pacemaker implantation, stroke, and myocardial infarct are other major complications following TAVI. ${ }^{[9]}$ Blocking the coronary ostia and limiting the anterior mitral leaflet mobility and atrioventricular (AV) conduction system are some frequently encountered perioperative complications. ${ }^{[10]}$

Prosthesis embolization immediately after deployment is usually the result of prosthesis/annulus mismatch (implantation of a prosthesis which has been undersized for the annulus), unduly high implantation, or ejection of the device by an effective ventricular contraction during deployment. Embolization to the aorta is usually well tolerated provided coaxial wire position is maintained, preventing the valve from flipping over to obstruct antegrade flow.

Retrograde migration of the prosthetic valve following TAVI is rare. It can occur during the procedure, within the first few days after the procedure or subsequently. The first step in developing a solution is to identify the contributing factors for migration. These range from prosthesis malpositioning (i.e., too low), suboptimal valve expansion, and uneven or insufficient aortic annulus calcification, leading to inadequate prosthesis fixation, aortic paravalvular regurgitation, valve undersizing, and anatomical or functional bicuspid valves.

Transcatheter heart valve (THV) migration into the left ventricle has been described 2-43 days after deployment and is associated with cardiogenic shock or disruption of mitral valve function. Mechanisms responsible for downward THV migration can include native leaflet overhang postdeployment, exerting downward force on the THV, or limited anchoring of the THV from low deployment in a relatively large and nonseverely calcified annulus or from deployment of a THV that is too small for the native aortic valve annulus. Although rare, delayed THV migration should be suspected when there is a worsening of the patient's clinical status or unfavorable THV hemodynamic profile (increasing mean gradient or worsening regurgitation) on follow-up echocardiographic examination.

\section{Conclusion}

Because it is the more recently used technique, we need much more time to detect the usefulness and complications of TAVI. With the latest time of migration (about 150 days), our case became so important for the complications of TAVI.

\section{Declaration of patient consent}

The authors certify that they have obtained all appropriate patient consent forms. In the form the patient(s) has/have given his/her/their consent for his/her/their images and other clinical information to be reported in the journal. The patients understand that their names and initials will not be published and due efforts will be made to conceal their identity, but anonymity cannot be guaranteed.

\section{Financial support and sponsorship \\ Nil.}

\section{Conflicts of interest}

There are no conflicts of interest. 


\section{References}

1. Charlson E, Legedza AT, Hamel MB. Decision-making and outcomes in severe symptomatic aortic stenosis. J Heart Valve Dis 2006;15:312-21.

2. Iung $\mathrm{B}$, Baron $\mathrm{G}$, Butchart EG, Delahaye $\mathrm{F}$, Gohlke-Bärwolf $\mathrm{C}$, Levang $\mathrm{OW}$, et al. A prospective survey of patients with valvular heart disease in Europe: The Euro Heart Survey on Valvular Heart Disease. Eur Heart J 2003;24:1231-43.

3. Varadarajan P, Kapoor N, Bansal RC, Pai RG. Clinical profile and natural history of 453 nonsurgically managed patients with severe aortic stenosis. Ann Thorac Surg 2006;82:2111-5.

4. Pai RG, Kapoor N, Bansal RC, Varadarajan P. Malignant natural history of asymptomatic severe aortic stenosis: Benefit of aortic valve replacement. Ann Thorac Surg 2006;82:2116-22.

5. Cribier A, Eltchaninoff H, Bash A, Borenstein N, Tron C, Bauer F, et al. Percutaneous transcatheter implantation of an aortic valve prosthesis for calcific aortic stenosis: First human case description. Circulation 2002;106:3006-8.

6. Piazza N, Wenaweser P, van Gameren M, Pilgrim T, Tzikas A, Otten A, et al. Relationship between the logistic EuroSCORE and the society of thoracic surgeons predicted risk of mortality score in patients implanted with the CoreValve reValving system - a bern-rotterdam study. Am Heart J 2010;159:323-9.

7. Leon MB, Piazza N, Nikolsky E, Blackstone EH, Cutlip DE, Kappetein AP, et al. Standardized endpoint definitions for transcatheter aortic valve implantation clinical trials: A consensus report from the valve academic research consortium. Eur Heart J 2011;32:205-17.

8. Zierer A, Wimmer-Greinecker G, Martens S, Moritz A, Doss M Is transapical aortic valve implantation really less invasive than minimally invasive aortic valve replacement? J Thorac Cardiovasc Surg 2009; 138:1067-72.

9. Wendler O, Thielmann M, Schroefel H, Rastan A, Treede H, Wahlers T, et al. Worldwide experience with the 29-mm edwards SAPIEN XTTM transcatheter heart valve in patients with large aortic annulus. Eur J Cardiothorac Surg 2013;43:371-7.

10. Johansson M, Nozohoor S, Kimblad PO, Harnek J, Olivecrona GK, Sjögren $\mathrm{J}$, et al. Transapical versus transfemoral aortic valve implantation: A comparison of survival and safety. Ann Thorac Surg 2011;91:57-63. 